\title{
Experimental Examination of the Relationship between Relative Performance Information, Goal Setting and Performance
}

\author{
Theodorus Radja Ludji
}

\begin{abstract}
Manuscript type: Research paper.

Research aims: This study experimentally examines the relationship between relative performance information (RPI), goal setting and performance. Hypotheses are developed based on social comparison theory, goal setting theory and relevant prior studies.

Design/Methodology/Approach: This study deploys multiple sessions of experiments with 110 undergraduate students as the participants. The two manipulated variables are the provision of RPI and the level of goal difficulty.

Research findings: Results from the experiment indicate that the presence of RPI is positively associated with performance, and an attainable goal is associated with high goal commitment and eventually, higher performance. More importantly, this study finds an interaction between RPI and goal commitment, where the positive effect of RPI on performance is more pronounced in a condition where individual's goal commitment is high.

Theoretical contributions/Originality: This study contributes to the accounting literature by providing empirical evidence that the
\end{abstract}

\footnotetext{
Theodorus Radja Ludji is a Lecturer at the Department of Accounting, Faculty of Business, Widya Mandala Catholic University Surabaya, Indonesia. Email address: theodorusradja@ ukwms.ac.id

This paper is based on my master thesis completed at Monash University. I thankfully appreciate the guidance from my supervisors, Axel Schulz, Dennis Fehrenbacher and Kristian Rotaru. I also thank two anonymous reviewers, AJBA Chief Editor, Area Editors and Language Editor for their insightful suggestions. Finally, I gratefully acknowledge the financial grants for this study obtained from Widya Mandala Catholic University Surabaya, and appreciate the support from the Department of Accounting, Monash University and the Indonesian Government through the Indonesian Endowment Fund for Education Scholarship (Beasiswa LPDP).
}

https://doi.org/10.22452/ajba.vol11no2.7 
positive effect of RPI on performance can be enhanced to a greater degree by individual's high commitment towards the assigned goal. Practitioner/Policy implications: This study has a practical implication by providing empirical evidence on how RPI and goal setting can be used strategically by firms to escalate employee's performance.

Research limitations/Implications: Limitations related to the types of RPI, goal levels and experiment task applied. Future studies may address these limitations and use a different type of task that is more closely associated with the current workplace situation.

Keywords: Relative Performance Information, Goal Setting, Performance, Experimental Examination

JEL Classification: M41

\section{Introduction}

In the contemporary workplace setting, firms typically use different forms of control systems to achieve their strategic objectives (Luft, 2016a; Mohamed, Wee, Abdul Rahman, \& Abdul Aziz, 2014). In this context, both the relative performance information (RPI) and goal setting elements are typical examples of the strategic control system (Frederickson, 1992; Locke \& Latham, 2006). Therefore, it becomes crucial for firms to decide whether or not to provide the RPI. The reason is because it may in turn affect employee's effort, motivation and eventually performance (Hannan, McPhee, Newman, \& Tafkov, 2013; Newman \& Tafkov, 2014). In addition, the level of goals assigned by firms to their employees is also regarded as an important factor that needs to be considered strategically, as it may motivate or demotivate employees (Kelly, Webb, \& Vance, 2015).

This study examines the relationship between RPI, goal setting and performance, emphasising on how the interaction between feedback element - manifested by RPI - and goal setting may affect individual's performance. Regarding the feedback-goal relationship, prior studies (Mahlendorf, Kleinschmit, \& Perego, 2014; Murthy \& Schafer, 2011) suggest that the presence of feedback may not necessarily have an effective influence toward performance if individuals are uncertain about the assigned goal. However, since the presence of RPI encourage individuals to demonstrate an outstanding level of performance in a publicly-observed situation to maintain their self-image (Frederickson, 1992; Tafkov, 2013), thus it is arguable that this encouragement may be perceived differently among individuals based on their commitment 
toward the assigned goal. For individuals with high commitment toward the goal, it is predicted the presence of RPI will in turn bring an additional incentive for them to demonstrate a substantial level of performance since the goal is considered attainable from their perspective (Locke \& Latham, 2002).

Multiple sessions of experiments with two manipulated variables were conducted to test the hypotheses in this study. The first manipulated variable, RPI provision, was manipulated as either present or absent. Meanwhile, goal difficulty as the second manipulated variable was operationalised as either attainable or unattainable. This difference in terms of goal difficulty will in turn determine the goal commitment perceived by individuals, where it is shown that attainable goal will lead to high goal commitment perceived by the individual; and conversely, unattainable goal results in low goal commitment. Specifically, this study investigates whether the presence of RPI and different levels of goal commitment perceived by individuals will in turn bring an influence toward performance. The results of the first and second hypothesis in this study indicate that the presence of RPI brings a positive influence toward individual's performance, and that an attainable (unattainable) assigned goal leads to higher (lower) goal commitment perceived by individuals and eventually higher (lower) performance.

More essentially, results from the third hypothesis in this study indicate an interaction between RPI and goal commitment on performance, where the positive effect of RPI on performance is enhanced to a greater degree in a condition where individual's goal commitment is high. This result is consistent with the concept of social comparison theory, which assumes that individuals tend to put more effort to maintain positive self-image in a publicly-observed situation (Tafkov, 2013; Webster, Duvall, Gaines, \& Smith, 2003); and goal setting theory, which posits that attainable goal will keep individual's effort at the level that is in line with the goal achievement (Locke, 1996). It is argued that the presence of RPI creates an incentive and motivation for individuals with high goal commitment to outperform others in a publicly-observed setting since the presence of RPI has been shown to motivate individuals to exert more effort (Kramer, Maas, \& Rinsum, 2016; McFarland \& Miller, 1994), and that a high level of goal commitment itself reflects the individual's unwillingness to neglect the current goal attainment process (Hollenbeck \& Klein, 1987).

By examining the effect of RPI and goal setting elements on performance, this study contributes to the behavioural management 
accounting literature, particularly related to the stream of research investigating the feedback provision, goal setting and individual performance. Although the outcome of RPI provision has been extensively examined in previous studies (Frederickson, 1992; Hannan et al., 2013; Tafkov, 2013) there are still limited evidences that could be drawn regarding the relationship between RPI, goal-setting elements and individual's performance. As one of the purposes of an organisation's control system is to ensure that employee's actions are in line with the organisation's best interests (Luft, 2016a; 2016b), this study contributes to the stream of accounting literature by demonstrating an experimental evidence on how the interaction between feedback - represented by the RPI - and goal-setting elements - manifested by goal difficulty and goal commitment - could eventually affect employee's performance.

Furthermore, this study also provides a practical contribution that can be considered by decision makers in terms of which control system that needs to be selected to motivate employees and to achieve the organisation's objective. The findings of this study indicate that by implementing RPI and maintaining a high goal commitment level perceived by the individual, the organisation can get an additional benefit as the interaction between RPI and high goal commitment level will positively affect performance as a result of the attainable goal. As firms frequently disinclined to provide RPI due to its possibly detrimental outcome (Hannan et al., 2013), this study therefore provides empirical evidence from which the presence of RPI can be used strategically by a firm alongside goal setting elements to escalate employee's performance.

The remainder of this study is structured as follows. Section 2 provides a literature review and hypotheses development, section 3 outlines the research method, section 4 presents the results and section 5 provides the discussion and implications. Finally, section 6 discusses the future research and limitations.

\section{Literature Review and Hypotheses Development}

\subsection{Relative Performance Information (RPI) and Performance}

Since the workplace situation has changed substantially such that cooperation and competition among employees - with its potential benefits and drawbacks - are almost inevitable in the contemporary workplace setting (Luft, 2016a), organisations thus need to react accordingly by implementing relevant control systems (Hilton \& Platt, 
2011; Luft, 2016a). One of the control systems that can be applied by the management is the relative performance information (RPI). In general, RPI can be regarded as information about relative performance of individuals or groups in a specific condition that can be used for evaluation purpose (Luft, 2016a; Mahlendorf et al., 2014). Social comparison theory (Festinger, 1954) highlighted the importance of the presence of RPI, as it is posited that individuals tend to compare their ability and performance with their colleagues that are identically comparable in relations to the characteristics or conditions. The result of this comparison is essential, as it may affect individual's own selfimage (Festinger, 1954; McFarland \& Miller, 1994). Thus, whether or not to provide RPI to employees will be an important issue to be considered by firms, since there are potential benefits and drawbacks associated with the RPI itself (Luft, 2016a). In this regard, Tafkov's (2013) study demonstrated that the provision of RPI can positively affect performance, as the presence of RPI would encourage individuals to "prove themselves" that they are capable of demonstrating a substantial degree of performance in front of their colleagues. However, as noted by Hannan et al. (2013), when there is a competing demand and discretion in effort allocation, the provision of RPI may in turn encourage people to switch their effort allocation to maintain their own self-image even if such action is against the firm's best interest.

Based on these arguments, the first hypothesis in this study is concerned with the effect of RPI on performance. In this case, it is posited that a social comparison element will be manifested by the presence of RPI as it facilitates people to compare their performance with peers in a publicly observed setting (Kramer et al., 2016; Newman \& Tafkov, 2014). Furthermore, it is argued that the presence of RPI can result in either positive or negative self-image perceived by individuals. Positive self-image resulting from outstanding public performance in a situation when RPI is present may create favourable conditions, such as positive feeling and pride (Webster et al., 2003), while a negative selfimage resulting from low performance in the RPI present situation may result in an unfavourable feeling such as shame (Coffey \& Maloney, 2010; Tafkov, 2013). The presence of RPI therefore would motivate individuals to exert more effort to maintain their own self-image in a publicly comparable situation (Hannan, Krishnan, \& Newman, 2008). It is therefore expected that individuals' performance will be higher when RPI is present than when it is absent. The hypothesis is therefore stated as follows: 
$\mathrm{H}_{1}$ : Individual's performance will be higher in a condition when the RPI is present than when the RPI is absent.

\subsection{Goal Difficulty, Goal Commitment, and Performance}

Goal is an important element of an organisation's control and performance measurement system (Klein, 1991). In this regard, one of the main factors that is frequently applied as an evaluation point regarding employees' performance is whether they can attain a specific goal assigned by the organisation (Latham \& Locke, 1991). Goal setting theory (Locke, 1996) posits that a goal would be effective if it is explicitly stated, challenging and considered to be attainable. If a goal is explicit, challenging but considered to be unattainable from an individual's viewpoint, then the goal may not be effective as the individual perceive that the goal is out of reach (Kelly et al., 2015; Lee, Keil, \& Wong, 2015). Furthermore, from the perspective of goal setting theory it is also outlined that individuals are concerned with the outcome of their effort in the goal attainment process, since it would in turn determine their commitment to achieve the goal (Locke \& Latham, 2002; 2006). If the assigned goal is regarded to be unreachable, then this would lead to a downward adjustment of the individual's goal commitment, and ultimately result in a decrease in performance (Klein, 1991; Klein \& Wright, 1994). For this reason, the second hypothesis in this study will be focussed on examining the effect of goal difficulty on goal commitment perceived by individuals. In line with the goal setting theory (Locke, 1996), it is essential to examine the relationship between goal difficulty and goal commitment, as prior studies (Hollenbeck \& Klein, 1987; Hollenbeck, Williams, \& Klein, 1989) argued that individuals' performance will be affected by their commitment towards the assigned goal, and this commitment was initially determined by the level of the goal assigned by the organisation.

In terms of the difference between attainable and unattainable goal, prior studies (Bonner \& Sprinkle, 2002; Lee, Locke, \& Phan, 1997) typically indicated that a goal is attainable if it can be attained by at least fifty per cent of individuals in a specific goal attainment condition. On the other hand, an unattainable goal generally referred to a goal that is set at a point that is not attainable by a majority of individuals (Fatseas \& Hirst, 1992; Wright, 1992). In terms of the relationship between goal difficulty and commitment, Locke (1996) argued that higher commitment toward the assigned goal can be achieved if the individual is convinced that the goal is still attainable at the first place. If a goal is 
unattainable; even though it is explicit and challenging; it may still decrease an individual's commitment toward the assigned goal (Klein \& Wright, 1994; Wright, 1992). This study therefore predicts that an attainable assigned goal will result in a higher goal commitment, and an unattainable goal will lead to a lower goal commitment. Thus, the hypothesis is stated as follows:

$\mathrm{H}_{2 \mathrm{a}}$ : An attainable goal will result in higher goal commitment and an unattainable goal will result in lower goal commitment.

In a context when an assigned goal is applied, it is essential to examine the effect of an employee's commitment toward the goal, as it has been indicated by prior studies (Locke \& Latham, 2002; Presslee, Vance, \& Webb, 2013) that individual's performance would be affected by his/her commitment toward the assigned goal. In line with the goal setting theory (Locke, 1996), an individual's goal commitment therefore becomes an essential factor that initiate motivation and effort, which will subsequently affect performance. It is documented by prior studies (Hollenbeck \& Klein, 1987; Klein \& Wright, 1994) that individuals with higher goal commitment will be more persistent when it comes to the goal attainment process than individuals with lower goal commitment since commitment towards a goal may encourage individual to exert more effort to attain the assigned goal. Thus, it is predicted that individuals with higher goal commitment - resulting from an attainable goal - would perceive that the goal is still within their capacity, which would lead them to become more persistent for the goal attainment process, thus eventually resulting in higher performance. On the other hand, it is expected that individuals with lower goal commitment with an unattainable assigned goal - will be more reluctant to exert a substantial level of effort required to attain the goal as it is regarded to be out of reach, and it would lead to a lower performance. Thus, it is predicted that individuals with higher goal commitment will have higher performance than individuals with lower goal commitment. The hypothesis is therefore stated as follows:

$\mathrm{H}_{2 b}$ : Performance will be higher for individuals with high goal commitment than for individuals with low goal commitment.

\subsection{Interaction between RPI and Goal Commitment on Performance}

Prior studies indicated that the effect of RPI on performance can be examined through both economic (Frederickson, 1992; Holmstrom, 1982) 
and behavioural perspectives (Hannan et al., 2013; Tafkov, 2013). From the economic perspective, it is posited by Holmstrom (1982) that the presence of RPI will enable principal to capture agent's unobservable actions by filtering out common uncertainty. Nonetheless, economic perspective underpins that employees exert their effort merely for monetary purposes, such as to obtain compensation or performancerelated bonuses (Kramer et al., 2016; Newman \& Tafkov, 2014). Thus, it is argued that if individuals are not rewarded based on their relative performance, then the presence of RPI may not affect one's performance as there is no incentive for an individual to outperform others, under such condition (Tafkov, 2013).

Nevertheless, from the behavioural perspective, it is argued that individuals also exert their effort for non-monetary purposes such as pride-seeking and desire to establish a positive self-image among colleagues (Greenberg, Ashton-James, \& Ashkanasy, 2007), even though they would not be rewarded based on their relative performance (Wood, 1996). Social comparison theory (Festinger, 1954) posits that individuals tend to compare their ability and performance with peers that are similar in terms of characteristics (e.g. the same level in the company) or condition (e.g. assigned the same task). It is also posited that individuals tend to compare themselves with peers or with objective benchmarks - such as performance standard - for self-evaluation purpose (Brown, Harris, Feller, \& Keeping, 2007; Nordstrom, Lorenzi, \& Hall, 1991). Therefore, an individual's tendency to utilise more effort in a publiclyobserved situation, even if the compensation was not based on relative performance, is an example of a situation when the presence of RPI creates a "behavioural effect" that affect individual's behaviour (Hannan et al., 2013; Wood, 1996).

For the feedback-goal setting relationship, prior studies (Mahlendorf et al., 2014; Murthy \& Schafer, 2011) showed that the behavioural effect of the relative performance feedback may effectively influence one's behaviour. This occurs when the individuals are aware about what they need to achieve, whether these can be achieved, and if so, how they can be achieved (Murthy \& Schafer, 2011). The relative feedback itself may not work effectively in a situation when an objective - or something that needs to be aimed for - was deemed to be uncertain (Hannan et al., 2008; Murthy \& Schafer, 2011). Hence, it is argued that the presence of feedback, manifested by the RPI with its behavioural element, would influence performance more effectively with the inclusion of goal setting elements. 
Therefore, it is predicted that the presence of feedback, which is reflected by the provision of RPI, and the goal setting element as manifested by goal commitment would interact and ultimately affect performance. As the presence of RPI as a relative feedback will provide information about the individual's relative performance in a publiclyobserved setting, this would facilitate self-awareness and self-evaluation for individuals, since the presence of RPI will allow individuals to observe both their relative standing against the assigned goal and their comparable position among peers (Kramer et al., 2016; Tafkov, 2013). Given that the monetary incentive is not provided based on individual's absolute or relative performance, thus the behavioural effect of RPI will be decidedly manifested in such a condition (Hannan et al., 2013). The extent to which the RPI will influence individuals with an assigned goal would depend on the individual's goal commitment level. For individuals with high goal commitment, the presence of RPI will more likely bring a greater motivational influence regarding the feedbackgoal relationship, compared to individuals with low goal commitment. Since attainable goals are more likely to lead to high goal commitment, it is therefore expected that highly committed individuals will be more motivated to achieve or even surpass the assigned goal when the RPI is present (McFarland \& Miller, 1994).

Previously, it is expected that highly committed individuals are more certain in achieving the assigned goal than their counterparts since the goal level is different. Thus, it is expected that the presence of RPI will in turn provide a behavioural-related incentive, in the form of a positive self-image, for highly committed individuals in such condition. This would happen if an outstanding level of performance can be demonstrated by highly committed individuals in a publicly-observed situation when the RPI is present. Since an attainable goal would lead to higher goal commitment than an unattainable goal, it is argued that a higher performance in a situation when the RPI is present will more likely be derived from individuals with high, rather than low, goal commitment. This is because the goal is attainable and the presence of RPI would encourage individuals to demonstrate a substantial level of performance to maintain their self-image.

It is previously predicted in $\mathrm{H}_{1}$ and $\mathrm{H}_{2 b}$ that both the RPI and individual's goal commitment will separately bring an influence on performance. Thus, the third hypothesis in this study will in turn predict an interaction effect between RPI and goal commitment toward 
individual's performance. Recall that $\mathrm{H}_{1}$ expects that the presence of RPI will positively affect performance. Meanwhile, it is predicted by $\mathrm{H}_{2 \mathrm{~b}}$ that higher goal commitment will lead to higher performance and vice versa, where the commitment was initially determined by the level of difficulty of goal assigned. It is therefore expected in $\mathrm{H}_{3}$ that when RPI is present, performance will be higher for individuals with high, rather than low, goal commitment. Here, the positive effect of RPI on performance that previously exists will be enhanced to a greater degree when individual's commitment toward the assigned goal is high. The hypothesis is formally stated as follows:

$\mathrm{H}_{3}$ : The positive effect of RPI on performance will be more pronounced among individuals with high goal commitment than those with low goal commitment.

Figure 1 summarises the hypotheses proposed in this study.

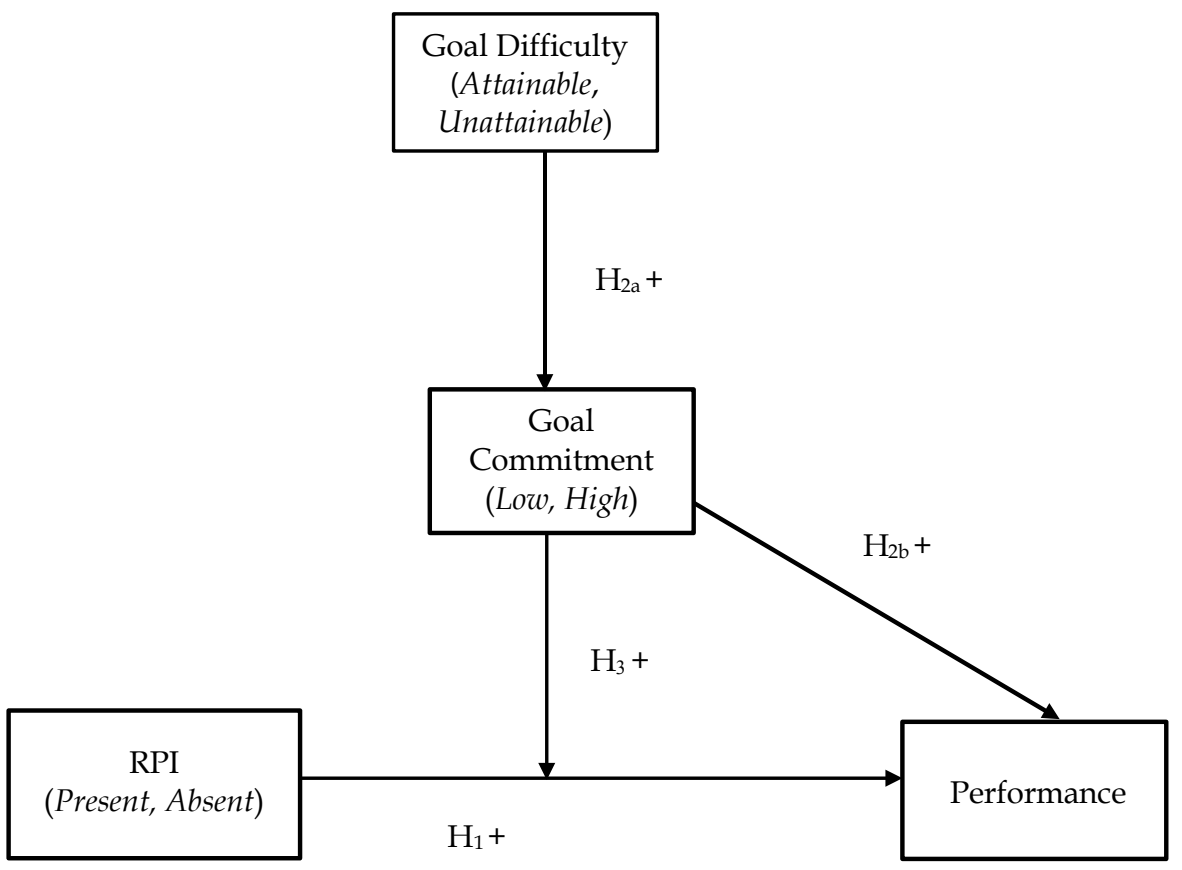

Figure 1: Summary of Hypotheses 


\section{Method}

\subsection{Experiment Design}

A $2 \times 2$ between-subject experiment design is applied to test the hypotheses. In this setting, the presence of RPI (present and absent) and the level of goal difficulty assigned to the participants (attainable and unattainable) are varied across four different conditions: (1) RPI PresentAttainable Goal; (2) RPI Present-Unattainable Goal, (3) RPI AbsentAttainable Goal; and (4) RPI Absent-Unattainable Goal. The treatment provided in these four experimental conditions are different from each other. For instance, in the first condition (RPI Present-Attainable Goal) participants will be provided with the RPI and an attainable assigned goal. In the fourth condition (RPI Absent-Unattainable Goal) participants will not receive any RPI and the goal assigned to the participants will be set at an unattainable level. The instrument used in this experiment was adapted from Tafkov's (2013) study, with adjustments related to the task instruction and experimental session overview.

There are five rounds conducted in each session, thus every round is a within-subject element. This is in line with Tafkov's (2013) study, where the number of rounds applied were constantly held for all participants across all conditions. Although there were four different between-subject conditions as specified above, where participants allocated in one condition will be given a different treatment from the others, all participants were required to solve the same set of multiplication problems (A, B, C, D and E) within five rounds applied in each experiment condition, similar with Tafkov's (2013) study. The multiplication problems given in each round is different, for instance, in round 1 participants will be provided with set $\mathrm{A}$ of multiplication problems, while set $B$ of multiplication problems will be given in round 2 , and so on. Table 1 displays the four experiment conditions applied in this study.

Similar with Tafkov's (2013) study, the dependent variable in this study is the individual's performance which was determined by the average number of multiplication problems correctly solved by participants in each round. Participants were provided with a fixed amount of participation fee of AUD6 for their participation in one experiment session that generally lasted for about 45 minutes. The compensation was held constant, regardless of the participant's performance, across all conditions. This to ensure that the hypotheses formulated in this study can be more precisely examined. Additionally, 
Table 1: Experiment Conditions

\begin{tabular}{|c|c|}
\hline Cell 1: & Cell 2: \\
\hline $\begin{array}{l}\text { Condition 1: RPI Present-Attainable } \\
\text { Goal }\end{array}$ & $\begin{array}{l}\text { Condition 2: RPI Present-Unattainable } \\
\text { Goal }\end{array}$ \\
\hline $\begin{array}{l}\text { Task: Solving a set of multiplication } \\
\text { problems (A-E) from Round 1-5 }\end{array}$ & $\begin{array}{l}\text { Task: Solving a set of multiplication } \\
\text { problems (A-E) from Round 1-5 }\end{array}$ \\
\hline Cell 3: & Cell 4: \\
\hline $\begin{array}{l}\text { Condition 3: RPI Absent-Attainable } \\
\text { Goal }\end{array}$ & $\begin{array}{l}\text { Condition 4: RPI Absent-Unattainable } \\
\text { Goal }\end{array}$ \\
\hline $\begin{array}{l}\text { Task: Solving a set of multiplication } \\
\text { problems (A-E) from Rounds } 1-5\end{array}$ & $\begin{array}{l}\text { Task: Solving a set of multiplication } \\
\text { problems (A-E) from Rounds } 1-5\end{array}$ \\
\hline
\end{tabular}

participants were required to complete a set of post-experimental surveys upon the completion of the last experiment round. The purpose of this survey was to collect participants' responses relating to a set of questions for goal commitment, RPI, task-related questions and demographic questions, since participants' responses are essential for the results analysis.

\subsection{Experiment Task}

During the experiment, participants are required to solve a set of "paper-and-pencil" multiplication problems. There are 30 multiplication problems for each round. As each session consists of five rounds, therefore it yields a total of five sets of problem (A, B, C, D and E) for five experimental sessions. To answer the problems, participants were told that they cannot select more than one answer for each problem. They are not allowed to write anything else on the answer sheet, except a sign (such as a circle or a cross) that indicate their answers. Participants were also required to answer those problems without the usage of any calculation devices and scratch papers. Each problem consists of a "two digits-by-two digits" multiplication problem, such as " $29 \times 66$ " as displayed in Figure 2.

$$
29 \times 66=\text { A) } 1914 \text { B) } 1799 \text { C) } 1844 \text { D) } 2107 \text { E) } 2054
$$

Figure 2: Example of Multiplication Problem 
Since participants were recruited from the undergraduate level of study, the implementation of "two digits-by-two digits" multiplication problems with "paper-and-pencil" approach was deemed to be suitable, as it does not require specific prior knowledge to be possessed by participants (Bonner, Hastie, Sprinkle, \& Young, 2000). In line with Tafkov's (2013) study, it is expected that the task applied in this study will satisfy the three requirements for a relationship between social comparison and competitive behaviour. The first requirement is the comparison task similarity, where the task must be similar for each participant to be comparable (Tafkov, 2013). This was ensured by applying the same multiplication problems with the same order $(\mathrm{A}, \mathrm{B}, \mathrm{C}$, $\mathrm{D}$ and $\mathrm{E}$ ) that need to be solved by participants across all sessions.

The second requirement is the comparison target similarity, where participants need to be recruited from the same source or study level to establish the awareness of social comparison factor in the RPI (Hannan et al., 2013; Tafkov, 2013). In this study, participants were recruited from the same undergraduate unit subject from a large public university in Australia to ensure comparison target similarity. The third requirement is the importance of comparison's domain (Tafkov, 2013). Since multiplication task requires problem-solving ability from individual without the usage of any calculation devices within a specific length of time, it is therefore expected that any differences related to participant's performance shall be attributed to the difference in their ability (Hannan et al., 2013; Tafkov, 2013).

\subsection{Research Variables}

The first independent variable in this study is the RPI, which was manipulated as either present or absent. The RPI present condition is applied based on "public-type RPI" in Tafkov's (2013) study where participants are provided with their relative performance rank, consisting of both their own performance and the performance of other participants in the same session. The RPI absent condition was conducted based on "no-RPI" condition (see Tafkov, 2013) where no performance-related information is provided to the participants. In the RPI present condition, participants were informed that their relative performance will be displayed on a public screen at the end of rounds 2 and 4 . The public screen itself is a large-sized projected screen that is used to display the slides that comprise participants' 


\section{Relative feedback for round 1 and 2}

Rank

Participant in Seat 1

Participant in Seat 2

Participant in Seat 3

Participant in Seat 4

Participant in Seat 5
Rank 4

Rank 1

Rank 2

Rank 5

Rank 3
Problems solved correctly

Round 1

Round 2

9

10

20

19

18

15

8

7

16

Figure 3: Example of a Slide for RPI Provision

relative performance. This can be viewed by all participants involved in that session. Figure 3 shows an example of RPI provision in the RPI present condition.

The provision of RPI at the end of round 2 displayed participants' performance for rounds 1 and 2, while the provision of RPI at the end of round 4 displayed the participants' performance in rounds 3 and 4 . As indicated in Tafkov's (2013) study, this arrangement would enable the RPI to capture a substantial range of participant's performance. When the RPI was presented, it was projected through a large public screen that can be viewed by all participants in that session. This will allow all participants to observe both their own performance and the performance of the other four participants. The RPI however, was not displayed based on rank order, as a previous study (Kramer et al., 2016) indicated that whether or not in a rank order, there was no difference in the participants' perception towards the provision of RPI. As in previous RPI-related studies (Hannan et al., 2013; Tafkov, 2013), this study also involves five participants for each session in the RPI present condition. This helps to establish the social comparison awareness among the participants. Previous studies (Hannan et al., 2013; Tafkov, 2013) indicated that the salience of the social comparison element in RPI provision will be more perceived by individuals when they are placed in a small-group setting. 
The second manipulated variable is the goal difficulty that is manipulated at either attainable or unattainable. The goal is related to the number of problems that needs to be solved correctly by the participants. A total of 30 problems are developed for each round. Based on the pilot tests conducted with 27 participants prior to the experiment, attainable goal is set at nine (9) correct answers which equals the 50th percentile of pilot tests result. Unattainable goal is set at 25 correct answers, where no participant in the pilot tests could attain. The reference point of these difficulty levels is based on prior literature (Bonner \& Sprinkle, 2002; Fatseas \& Hirst, 1992; Lee et al., 1997), where an attainable goal is typically set at a point that can be achieved by at least fifty per cent of participants, and an unattainable goal is set at a point that cannot be achieved by all participants. However, as discussed previously, participants were told that their pay will not be affected by attaining or not attaining the goal.

Following the end of the experiment session, participants are required to complete a short survey related to their goal commitment. A set of questions adapted from Presslee et al. (2013) is used to measure participant's goal commitment. Here, participants are required to indicate their perception relating to the commitment toward a specific goal that has been explicitly assigned to them. The goal itself is set either at an attainable level (9 correct answers) or at an unattainable level (25 correct answers) depending on a randomly-allocated experiment session that they participated in. The set of questions itself comprises a five-point scale, ranging from "strongly disagree" (1) to "strongly agree" (5) with higher average score indicating higher goal commitment and vice versa.

The dependent variable in this study is the individual's performance that is determined by the number of multiplication problems correctly solved by the participant in each round. There are 30 multiplication problems in total for each round, or 150 problems available in total for all five rounds in one experiment session. Maximum number of problems that can be answered correctly by one participant in each round is 30 and the minimum is 0 (zero). The problems need to be solved by participants without any calculation devices.

\subsection{Experiment Participants}

Participants were recruited from an undergraduate commerce-business major at a large public university in Australia. At the initial stage, 140 undergraduate students participated in this study. Since the participants 
randomly allocated themselves into the opening slots for each session, thus it appeared that four sessions - two from RPI Present condition and two from RPI Absent condition that involved 20 participants in total were conducted with the same treatment. In this regard, 20 participants were excluded to prevent any sequential effects. Meanwhile, the RPI present condition required five participants for each session. However, in several schedules there are some participants that did not attend the experiment session. As a result, the experimenter had to change the schedule immediately from RPI present condition to RPI absent condition, so that the remaining participants (typically either three or four) can still participate in the session. One procedure that was subsequently implemented to anticipate this situation is to open the extra time slots for six participants. This was meant to accommodate the participants who were absent on the day when the experiment was conducted. In this case, if all six participants are present, then five participants would be allocated to the RPI present condition, while one participant will be allocated to the RPI absent condition.

To precisely analyse the results in this study, a median split is conducted to categorise participants to either low or high goal commitment level, based on their median score. Since the median score of goal commitment is 3.4, thus the average scores below the median $(<3.4)$ are categorised as "low goal commitment" (coded as "1") and scores above the median (>3.4) are classified as "high goal commitment" (coded as "2"). Participants with goal commitment score equal to the median $(n=10)$ are excluded. This yielded 59 participants in the category of low goal commitment, 51 participants for high goal commitment, and a total of 110 participants taken for the results analysis. Table 2 displays a summary of the sessions and participants' information.

The average age of participants in this study is 20.6 years and 65.5 per cent of them are female. Further analysis (not tabulated) indicate that there is no significant difference in age and gender across all four conditions in this study, and that the variety of age and gender across all experiment conditions do not bring any significant influence on performance and goal commitment scores (all $\mathrm{p}>0.18$, two-tailed), indicating that the randomisation process has been effectively implemented.

Participants are provided with written instructions at the beginning of the experiment, and the instructions are explained by the experimenter. As in Tafkov's (2013) study, participants are required to answer a set of questions prior to the start of the experiment to ensure that they clearly understand the instructions. There is no reduction 
Table 2: Sessions and Participants' Information

\begin{tabular}{lcc}
\hline Category & Sessions & Participants \\
\hline $\begin{array}{l}\text { Sessions conducted with complete participants in } \\
\text { RPI Present condition (5 participants for each session) }\end{array}$ & 14 & 70 \\
$\begin{array}{l}\text { Sessions conducted with complete participants in the } \\
\text { RPI Absent condition (5 participants for each session) }\end{array}$ & 9 & 45 \\
$\begin{array}{l}\text { Sessions conducted with } 4 \text { participants (RPI Absent } \\
\text { condition) }\end{array}$ & 5 & 20 \\
$\begin{array}{l}\text { Sessions conducted with } 3 \text { participants (RPI Absent } \\
\text { condition) }\end{array}$ & 1 & 3 \\
$\begin{array}{l}\text { Session conducted with } 1 \text { participant (RPI Absent } \\
\text { condition)* }\end{array}$ & 2 & 2 \\
\hline $\begin{array}{l}\text { Participants at the initial stage } \\
\text { Less: Participants in sessions that were conducted } \\
\text { with the same treatment in a row (5 participants for } \\
\text { each session) }\end{array}$ & 31 & 140 \\
$\begin{array}{l}\text { Usable sessions and participants } \\
\text { Less: Participants with goal commitment score equal } \\
\text { to the median } \\
\text { Number of participants taken for the results analysis }\end{array}$ & & $(20)$ \\
\hline
\end{tabular}

Note: * Resulting from the difference between 6 participants showing up minus 5 participants allocated to the RPI Present condition.

in terms of the number of participants at this stage, since any question that has been incorrectly answered are subsequently discussed by the experimenter with the participants. This is to ensure that there is no misperception, and to ensure that the participants are aware about what they need to perform before proceeding to the main rounds. Upon the completion of the questions, participants in the RPI present condition are required to introduce themselves to the other four participants in their session by standing up and giving their name, major and their seat number. In line with prior RPI-related studies (Hannan et al., 2013; Tafkov, 2013), this is done to eliminate anonymity among participants, since the relative performance rank will be provided in their session.

Participants in all four conditions in this study are required to complete five main experimental rounds with each round lasting 5 minutes. As in Tafkov's (2013) study, to avoid the "end game strategy", 
participants are not told in which round the experiment will be finished. Before the start of round 1, the experimenter sets a certain goal for all participants in the session based on their experiment condition (attainable or unattainable goal). The goal was either nine (9) for attainable condition or 25 for unattainable condition. These goals will be the same for all the five rounds of experiment. After the completion of round 5, participants were informed that the experiment is finished. Participants then complete a set of post-experimental survey. Finally, each participant's compensation of AUD6 were provided after they have completed the survey and the experiment session is finished.

\section{Results}

\subsection{Descriptive Statistics}

As mentioned earlier, to precisely analyse the results, a median split is conducted to categorise participants to either low or high goal commitment level, based on their goal commitment average score which will be compared to the median of 3.4. Average scores below the median $(<3.4)$ were categorised as "low goal commitment" (coded as "1") and average scores above the median (>3.4) were classified as "high goal commitment" (coded as "2"). Participants with goal commitment scores that are equal to the median $(n=10)$ were excluded. In total, this yielded 110 participants for the result analysis. Table 3 displays the descriptive statistics.

Table 3 Panel A shows that the average performance is higher in RPI Present (13.73) than in RPI Absent condition (11.00). Meanwhile, Panel B shows that the average goal commitment scores under attainable goal (3.47) are higher than the unattainable goal condition (3.04). Although still insufficient to draw any conclusions, it is argued that these patterns are in line with the predictions stated in $\mathrm{H}_{1}$ and $\mathrm{H}_{2 \mathrm{a}}$.

Figure 4 shows participants' average performance from rounds 1 to 5 in both RPI Present and RPI Absent conditions. It is shown that when RPI is present, the average performance gradually increased from round 1 (12.58) to round $2(12.80)$ and from round 3 (13.92) to round 4 (14.74). Since RPI is provided at the end of rounds 2 and 4 , these positive trends are in line with the timing when RPI is provided. These patterns indicate that participants tend to perform better in rounds where RPI is present (rounds 2 and 4 ) as a means of compensating the lower performance shown in previous rounds before RPI is presented (rounds 
Relationship between Relative Performance Information, Goal Setting and Performance

Table 3: Descriptive Statistics (Mean and Standard Deviation)

\begin{tabular}{lccc}
\hline Conditions & RPI Present & RPI Absent & Row Average \\
\hline Panel A: Performance & & & \\
Attainable goal & $13.99(5.71)$ & $10.89(3.17)$ & $12.44(4.83)$ \\
& $n=27$ & $n=27$ & $n=54$ \\
Unattainable goal & $13.49(4.84)$ & $11.10(4.27)$ & $12.29(4.68)$ \\
& $n=28$ & $n=28$ & $n=56$ \\
Column average & $13.73(5.25)$ & $11.00(3.74)$ & $12.36(4.74)$ \\
& $n=55$ & $n=55$ & $n=110$ \\
\hline Panel B: Goal Commitment & & & \\
Attainable goal & $3.47(0.57)$ & $3.47(0.53)$ & $3.47(0.54)$ \\
& $\mathrm{n}=27$ & $\mathrm{n}=27$ & $\mathrm{n}=54$ \\
Unattainable goal & $3.05(0.69)$ & $3.03(0.87)$ & $3.04(0.78)$ \\
& $\mathrm{n}=28$ & $\mathrm{n}=28$ & $\mathrm{n}=56$ \\
Column average & $3.25(0.66)$ & $3.25(0.75)$ & $3.25(0.71)$ \\
& $\mathrm{n}=55$ & $\mathrm{n}=55$ & $\mathrm{n}=110$ \\
\hline
\end{tabular}

Notes: There are four conditions in the experiment: Cell 1: RPI Present-Attainable goal, Cell 2: RPI Present-Unattainable goal, Cell 3: RPI Absent-Attainable goal, and Cell 4: RPI Absent-Unattainable goal. RPI was manipulated in two conditions. In RPI Present condition, participants are provided with information about both their own performance and performance of other participants in the same condition. In RPI Absent condition however, there is no performance information provided, both for personal and relative category of performance. Goal difficulty is manipulated in two conditions. In the Attainable Goal condition, participants are provided with a goal of 9 out of 30 multiplication problems for each round. In the Unattainable Goal condition, participants are provided with a goal of 25 out of 30 multiplication problems. Performance refers to the average number of multiplication problems that can be answered correctly by participants in each experimental session. Maximum number of problems that can be answered correctly in each round is 30 and the minimum is 0 (zero). Goal commitment score reflects the average scores of participants' answers to a set of five-point scaled questions about goal commitment adapted from Presslee et al.'s (2013) study. There are five questions in total. Participants' answers are ranged from "strongly disagree" (1) to "strongly agree" (5). Questions 1, 2 and 4 are reversecoded as in Presslee et al.'s (2013) study. 


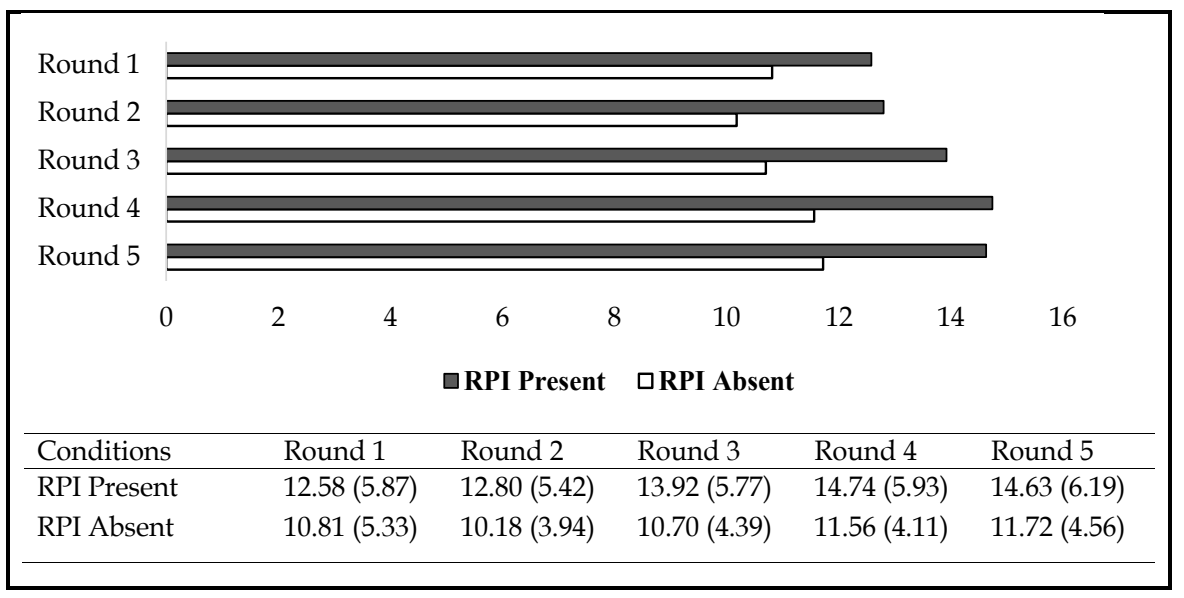

Figure 4: Performance Trends by Rounds (Mean and Standard Deviations)

1 and 3). As in Tafkov's (2013) study, it is argued that the presence of RPI and its social comparison element in this study has been anticipated by individuals, in accordance with the purpose of maintaining self-image among colleagues in a publicly-observed setting.

Similar with Tafkov's (2013) study, there are three requirements related to the relationship between social comparison and competitive behaviour that needs to be established regarding the presence of RPI. From the design of the experiment, the first and second requirements of the relationship between social comparison and competitive behaviour have been fulfilled. The first requirement (comparison task similarity) has been satisfied through the implementation of the same multiplication problems across all experimental conditions. The second requirement (comparison target similarity) has also been fulfilled as participants are recruited from the same undergraduate unit subject at a large public university in Australia.

The third requirement (the importance of comparison's domain) will be examined through the results of post-experimental questions displayed in Table 4 . The post-experimental survey consists of a set of questions with a five-point scale adapted from Tafkov's (2013) study, ranging from 1 to 5. In the RPI Present condition (Cells 1 and 2), participants' mean response regarding the question about the importance of general problem-solving ability, ranged from 1 (definitely yes) to 5 (definitely not), is 1.74 . This mean score is significantly different from the mid-point of 3 ( $\mathrm{t}=-11.372, \mathrm{p}<0.01$, two-tailed), indicating that a 
Table 4: Responses to Post-Experimental Questions (Mean and Standard Deviation)

\begin{tabular}{lcccccc}
\hline RPI & \multicolumn{3}{c}{ RPI Present } & \multicolumn{3}{c}{ RPI Absent } \\
\hline Goal difficulty & $\begin{array}{c}\text { Attainable } \\
\text { Goal } \\
\text { (Cell 1) }\end{array}$ & $\begin{array}{c}\text { Unattain- } \\
\text { able Goal } \\
\text { (Cell 2) }\end{array}$ & Total & $\begin{array}{c}\text { Attainable } \\
\text { Goal } \\
\text { (Cell 3) }\end{array}$ & $\begin{array}{c}\text { Unattain- } \\
\text { able Goal } \\
\text { (Cell 4) }\end{array}$ & Total \\
\hline Task difficulty & 3.18 & 3.78 & 3.49 & 3.62 & 4.21 & 3.92 \\
Task attractive- & $(1.07)$ & $(0.68)$ & $(0.94)$ & $(0.68)$ & $(0.78)$ & $(0.79)$ \\
ness & 2.40 & 2.96 & 2.69 & 2.74 & 3.07 & 2.90 \\
General problem- & $(1.18)$ & $(1.23)$ & $(1.23)$ & $(0.98)$ & $(1.41)$ & $(1.22)$ \\
solving ability & 1.59 & 1.89 & 1.74 & 1.96 & 1.78 & 1.87 \\
Perception & $(0.69)$ & $(0.91)$ & $(0.82)$ & $(1.01)$ & $(0.78)$ & $(0.90)$ \\
toward RPI & 2.51 & 2.64 & 2.58 & - & - & - \\
Attention to RPI & $(0.97)$ & $(0.98)$ & $(0.97)$ & & - & - \\
RPI and strategy & 2.85 & 2.82 & 2.83 & - & - & - \\
& $(0.94)$ & $(0.77)$ & $(0.85)$ & & & - \\
RPI and feelings & 2.55 & 2.82 & 2.69 & - & & - \\
& $(1.08)$ & $(1.18)$ & $(1.13)$ & & & - \\
\hline
\end{tabular}

Notes: Task difficulty represents participants' perception about how difficult the multiplication problems were. It is measured through a five-point scale, ranging from "very easy" (1) to "extremely difficult" (5). Task attractiveness represents participants' perception whether the multiplication problems were deemed to be interesting from their perspective. It is measured by a five-point scale, ranging from "very interesting" (1) to "not interesting at all" (5). General problem-solving ability reflects participants' assessment of whether a general problem-solving ability is regarded to be an important ability that needs to be possessed to succeed in career. It is measured by a five-point scale, ranging from "definitely yes" (1) to "definitely not" (5). Perception toward RPI (RPI Present condition only) reflects participants' assessment on how often that they thought about their own performance compared to other participants during the session. It is measured using a five-point scale, ranging from "never" (1) to "always" (5). Attention to RPI (RPI Present condition only) represents participants' response about how much attention they paid to the information about their relative performance ranking during the session. It is measured by a five-point scale, ranging from "none at all" (1) to "a great deal" (5). RPI and strategy (RPI Present condition only) reflects participants' perception on whether the relative performance ranking affects their strategy. It is measured through a five-point scale, ranging from "definitely yes" (1) to "definitely not" (5). RPI and feelings (RPI Present condition only) represents participants' perception about how they feel about their own performance relative to other participants. It is measured by a five-point scale, ranging from "very ashamed" (1) to "very proud" (5). 
majority of participants in RPI Present condition perceived that general problem-solving ability is important.

Furthermore, participants' mean response for the question about the perception toward RPI (2.58) is significantly different from the mid-point of $3(\mathrm{t}=-3.179, \mathrm{p}<0.01$, two-tailed), indicating that a majority of participants think considerably about their relative performance when RPI is present. The mean response for the question regarding RPI and strategy (2.69) is significantly different from the mid-point of 3 ( $t=-2.017, p=0.049$, two-tailed), indicating that the presence of RPI poses an influence toward participants' strategy. The mean responses for questions regarding the attention to RPI (2.83), and RPI and feelings (3.03) are not significantly different from the midpoint score (all $p>0.1$, two-tailed), yet further analysis (not tabulated) shows that a majority of responses for the question relating to attention to RPI is "a moderate amount" (47.3 per cent) indicating that a majority of participants paid a moderate amount of attention toward RPI when it is present.

In addition, the majority answers for the RPI and feelings question was "neither ashamed nor proud" (43.6 per cent), thereby showing that in general, participants are neither satisfied nor dissatisfied about their relative performance. It is therefore arguable that the requirement of the importance of comparison's domain has been satisfactorily represented through the presence of RPI, since the average responses for questions related to perception toward RPI and RPI and strategy are significantly different from the midpoint, and that the average responses for questions related to attention to RPI and RPI and feeling are regarded to be moderate and supported by the percentage of majority responses that indicated the moderate level of attention and feeling towards the RPI. Thus, it is expected that the presence of RPI would in turn, provide an incentive for participants to maintain their self-image by exerting more effort in condition when the RPI is present (Kramer et al., 2016; Tafkov, 2013).

\subsection{Hypotheses Testing}

$\mathrm{H}_{1}$ predicts that individual performance will be higher in a condition when RPI is present compared to a condition when RPI is absent. Table 5 displays the mean difference of performance for RPI present and absent conditions.

Table 5 shows that the average performance is higher in a condition when RPI is present (13.73) than in a condition when RPI is absent 
Table 5: Hypotheses Testing $\left(\mathrm{H}_{1}\right)$

\begin{tabular}{lcccc}
\hline RPI & Performance & t-statistics & Mean Difference & p-value \\
\hline RPI Present & $13.73(5.25)$ & 3.150 & 2.73 & $<0.01^{*}$ \\
RPI Absent & $11.00(3.74)$ & & & \\
\hline
\end{tabular}

Note: * The p-value is reported in one-tailed due to the directional prediction.

(11.00). The difference between average performances in these two conditions is significant ( $p<0.01$, one-tailed), indicating that the presence of RPI has positively affected the individual's performance. $\mathrm{H}_{1}$ is therefore supported.

$\mathrm{H}_{2 \mathrm{a}}$ predicts that an attainable goal will lead to higher goal commitment and conversely, an unattainable goal will result in lower goal commitment. Prior to the hypotheses testing, the measurements used to assess goal commitment are factor analysed. Table 6 displays the factor loadings and Cronbach's alpha indicator for these goal commitmentrelated questions. All the items loaded significantly, with values above 0.6 . Cronbach's alpha value is also found to be acceptable (>0.6). As in Presslee et al.'s (2013) study, questions 1, 2 and 4 are reverse coded.

Table 6: Goal Commitment Questions

Cronbach's Alpha

0.765

Questions

Factors Loading

1. It was hard to take the assigned goal seriously.*

0.721

2. Quite frankly, I did not care if I achieved the 0.662 assigned goal or not.*

3. I was strongly committed to pursuing the assigned goal.

4. It did not take much for me to abandon the goal.*

5. I think the assigned goal was good to aim for.

0.744

Note: * Reverse-coded as in Presslee et al.'s (2013) study.

Furthermore, Table 7 displays the mean difference of goal commitment scores in the attainable and unattainable goal conditions. The table indicates that the average goal commitment score is higher under attainable goal condition (3.47) than under unattainable goal condition 
Table 7: Hypothesis Testing $\left(\mathrm{H}_{2 \mathrm{a}}\right)$

\begin{tabular}{|c|c|c|c|c|}
\hline Goal difficulty & $\begin{array}{l}\text { Goal Commit- } \\
\text { ment Score }\end{array}$ & t-statistics & $\begin{array}{c}\text { Mean } \\
\text { Difference }\end{array}$ & $\mathrm{p}$-value \\
\hline Attainable goal & $3.47(0.54)$ & \multirow{2}{*}{3.326} & \multirow{2}{*}{0.43} & \multirow{2}{*}{$<0.01^{*}$} \\
\hline Unattainable goal & $3.04(0.78)$ & & & \\
\hline
\end{tabular}

Note: * The p-value is reported in one-tailed due to the directional prediction.

(3.04). The difference between average score of goal commitment in these two conditions is significant $(\mathrm{p}<0.01$, one-tailed) thereby indicating that attainable goal leads to higher goal commitment and conversely, an unattainable goal leads to lower goal commitment. $\mathrm{H}_{2 \mathrm{a}}$ is therefore supported.

$\mathrm{H}_{2 b}$ predicts that goal commitment will have a positive effect on performance, where individuals with high goal commitment will have higher performance than individuals with low goal commitment. Table 8 presents the result of the hypothesis.

Table 8: Hypothesis Testing $\left(\mathrm{H}_{2 b}\right)$

\begin{tabular}{llccc}
\hline $\begin{array}{l}\text { Goal commitment } \\
\text { level }\end{array}$ & Performance & t-statistics & $\begin{array}{c}\text { Mean } \\
\text { Difference }\end{array}$ & p-value \\
\hline Low & $11.03(3.58)$ & -3.319 & 2.87 & $<0.01^{*}$ \\
High & $13.91(5.43)$ & & & \\
\hline
\end{tabular}

Note: * The p-value is reported in one-tailed due to the directional prediction.

The results indicate that average performance was different between individuals with low goal commitment (11.03) and high goal commitment (13.91). The difference between these two conditions was significant $(p<0.01$, one-tailed) indicating that goal commitment positively affect performance, where individuals with high goal commitment eventually perform better than individuals with low goal commitment. This result supports $\mathrm{H}_{2 \mathrm{~b}}$.

$\mathrm{H}_{3}$ predicts an interaction effect that when the RPI is present, performance will be higher among individuals with high, rather than low, goal commitment. Table 9 Panel A displays the ANOVA result and Panel B shows the test of mean differences. 
Table 9: Hypothesis Testing $\left(\mathrm{H}_{3}\right)$

\begin{tabular}{lccrr}
\hline $\begin{array}{l}\text { Panel A: ANOVA Result } \\
\text { Source of Variation }\end{array}$ & $\mathrm{df}$ & Mean Square & \multicolumn{1}{c}{ F } & p-value \\
\hline RPI & 1 & 269.758 & 15.110 & $<0.01$ \\
Goal Commitment & 1 & 274.206 & 15.359 & $<0.01$ \\
RPI $^{*}$ Goal Commitment & 1 & 82.034 & 4.595 & 0.034 \\
Error & 106 & 17.853 & & \\
R-Squared $=0.228$ (Adjusted R-Squared $=0.206)$ & & \\
\hline
\end{tabular}

Panel B: Test of Mean Differences

\begin{tabular}{|c|c|c|c|}
\hline Category & RPI Present & RPI Absent & $\begin{array}{l}\text { Mean Difference } \\
\text { between Rows }\end{array}$ \\
\hline $\begin{array}{l}\text { Low Goal } \\
\text { Commitment }\end{array}$ & 11.68 (3.95) & $10.26(2.97)$ & $\begin{array}{c}1.41(0.92) \\
p=0.132\end{array}$ \\
\hline $\begin{array}{l}\text { High Goal } \\
\text { Commitment }\end{array}$ & $16.60(5.55)$ & $11.70(4.29)$ & $\begin{array}{c}4.89(1.37) \\
p<0.01\end{array}$ \\
\hline $\begin{array}{l}\text { Mean Difference } \\
\text { between Columns }\end{array}$ & $\begin{array}{c}4.91(1.28) \\
p<0.01\end{array}$ & $\begin{array}{l}1.44(0.99) \\
p=0.155\end{array}$ & $\begin{array}{c}\text { Column-row Average } \\
12.36(4.74)\end{array}$ \\
\hline
\end{tabular}

Panel C: Planned Contrast Analysis

\begin{tabular}{lccccc} 
Contrast & Value of Contrast & $\mathrm{SE}$ & $\mathrm{t}$ & $\mathrm{df}$ & $\mathrm{p}$-value \\
\hline Model Contrast & 15.370 & 6.234 & 2.465 & 106 & 0.015 \\
\hline
\end{tabular}

Note: RPI was manipulated in two conditions: RPI Present and RPI Absent. Goal Commitment score reflects the average scores of participants regarding their answers to a set of five-point scaled questions about goal commitment adapted from Presslee et al.'s (2013) study, ranging from "strongly disagree" (1) to "strongly agree" (5). Questions 1, 2 and 4 were reverse-coded as in Presslee et al. (2013). RPI ${ }^{*}$ Goal Commitment refers to the interaction between RPI and Goal Commitment. Participants were categorised as Low Goal Commitment if their average score of goal commitment were below the median score of 3.4. Participants were categorised as High Goal Commitment if their average score of goal commitment were above the median score of 3.4. The contrast coefficients to test $\mathrm{H}_{3}$ are: +6 for performance in RPI Present-High Goal Commitment condition, -1 for performance in RPI Present-Low Goal Commitment condition, -2 for performance in RPI Absent-High Goal Commitment condition, and -3 for performance in RPI Absent-Low Goal Commitment condition. 
Table 9 Panel A shows that the interaction effect between RPI and goal commitment on performance is significant $(\mathrm{F}=4.595, \mathrm{p}=0.034$, twotailed). Meanwhile, Panel B displays the average performance based on RPI and goal commitment. In RPI Present condition, individuals with high goal commitment shows higher performance (16.60) than individuals with low goal commitment (11.68) and the difference is significant ( $\mathrm{p}<0.01$, two-tailed). On the other hand, the difference in performance for individuals with high (11.70) and low (10.26) goal commitments in RPI absent condition is not significant $(p=0.155$, two-tailed). Furthermore, Panel B shows that in a condition of high goal commitment, performance is significantly higher when RPI is present (16.60) than when RPI is absent (11.70), and that the difference is significant ( $p<0.01$, two-tailed). However, in a condition of low goal commitment, the difference in terms of performance when RPI is present (11.68) and absent (10.26) is not significant ( $\mathrm{p}=0.132$, two-tailed). These results resemble an exact pattern with the prediction stated in $\mathrm{H}_{3}$.

Additionally, a planned contrast analysis is also performed to precisely examine $\mathrm{H}_{3}$. As in Tafkov (2013), each session is treated as one independent observation, where the contrast coefficients to test $\mathrm{H}_{3}$ are: +6 for performance in RPI Present-High Goal Commitment condition, -1 for performance in RPI Present-Low Goal Commitment condition, -2 for performance in RPI Absent-High Goal Commitment condition, and -3 for performance in RPI Absent-Low Goal Commitment condition. As shown in Panel C of Table 9, the result of planned contrast analysis displays a significant result $(\mathrm{t}=2.465$, significance $=0.015$, two-tailed), which indicates that performance shown in the condition of RPI PresentHigh Goal Commitment is significantly different from the performances shown in the other three conditions. This pattern is consistent with the prediction stated in $\mathrm{H}_{3}$.

Finally, Figure 5 illustrates the results as displayed in Panels A, B and C of Table 9. The figure shows that when RPI is present, individuals with high goal commitment have a significantly higher performance than individuals with low goal commitment. However, when RPI is absent, the difference between individuals' performance in both high and low goal commitment is not significant. Taken together the result of this analysis alongside previous $\mathrm{H}_{3}$-related analyses discussed above; it can be stated that the positive effect of RPI on performance becomes greater in a condition when individual's goal commitment is high. It can also be concluded that the interaction between the presence of 


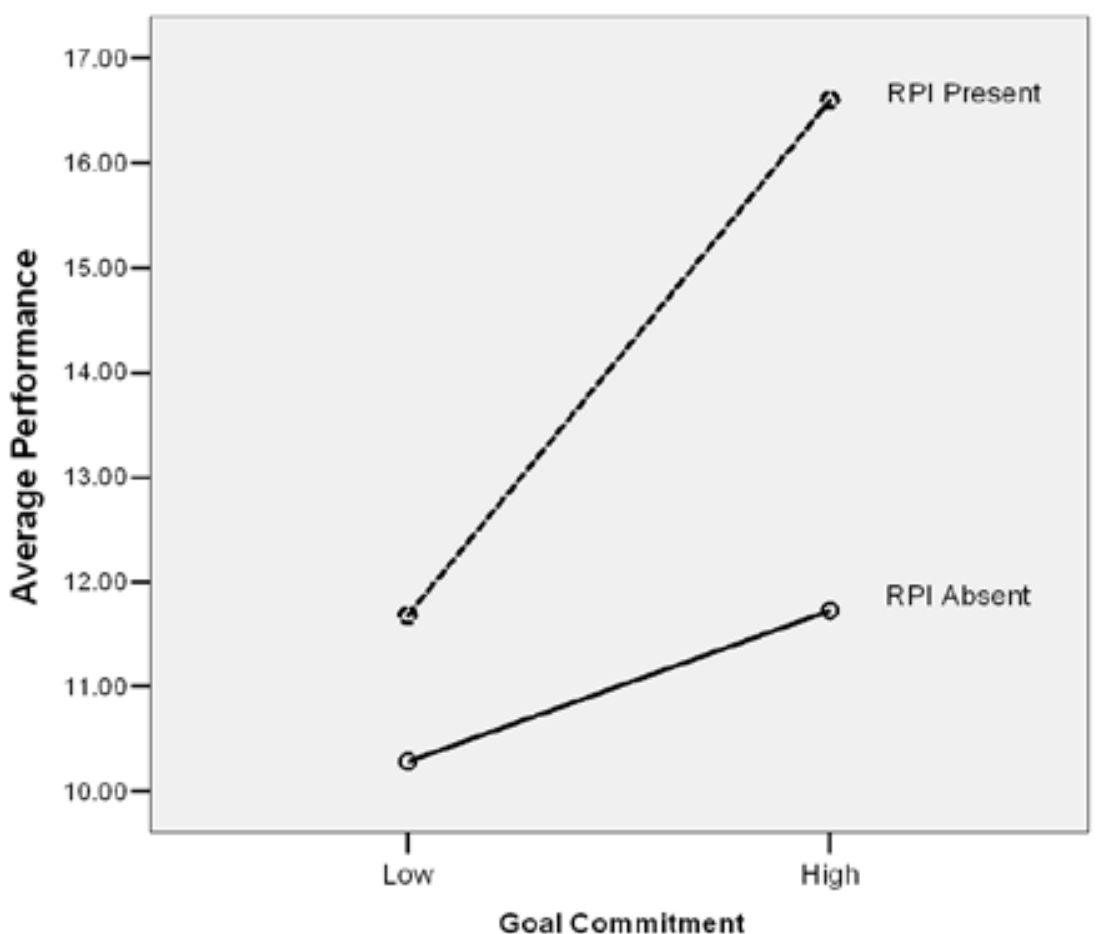

Figure 5: Hypothesis 3, Performance by RPI and Goal Commitment

RPI and high goal commitment perceived by individuals will in turn escalate individuals' performance to a higher level. This result provides support for $\mathrm{H}_{3}$.

\section{Discussion}

This study examines the relationship among RPI, goal setting and performance, focusing on how RPI and goal setting elements may affect performance. It is posited by social comparison theory (Festinger, 1954), that individuals tend to compare and evaluate their performance with comparable peers. As the social comparison element is manifested through the provision of RPI, prior studies (Kramer et al., 2016; Tafkov, 2013) showed that the presence of RPI may bring a behavioural effect by encouraging individuals to exert more effort in a publicly-observed situation. Furthermore, goal setting theory (Locke, 1996) assumes that the goal must be explicit, challenging and attainable to be effective. 
It is also posited that a different level of assigned goal may result in different levels of goal commitment (Wright, 1992; Lee et al., 2015). For the feedback-goal relationship, prior studies (Hannan et al., 2008; Mahlendorf et al., 2014) showed that the provision of relative feedback may not be effective when the objective that needs to be achieved by employees was perceived to be uncertain.

Results from this study indicate that performance is higher in a condition where the RPI is present than when it is absent. This is consistent with the concept of social comparison, where it is proposed that the behavioural effect of RPI will initiate such behaviour to happen for the purpose of maintaining self-image (Brown et al., 2007; Festinger, 1954). Furthermore, this study also finds that an attainable goal results in higher goal commitment and eventually higher performance. This is in line with the goal setting theory (Locke, 1996) where it was shown that firms may need to consider the level of goal assigned to employees since this can lead to different levels of goal commitment and eventually performance.

More importantly, this study finds an interaction between RPI and goal commitment on performance, where the positive effect of RPI on performance was enhanced to a greater degree among individuals with high - rather than low - goal commitment. This is displayed by the result of the third hypothesis where the highest level of performance has been shown in a condition when RPI is present among individuals with high goal commitment. This is essential, since it demonstrates that both the presence of RPI and individual's commitment toward the assigned goal will in turn interact and bring a significant influence towards performance. It is therefore argued that the interaction between RPI and high goal commitment perceived by individuals can escalate individual's performance to a higher level.

The plausible explanation for this result can be derived through both social comparison and goal setting perspectives. As the social comparison element is manifested through RPI, thus it will create a behavioural-related incentive for an individual to outperform others (Hannan et al., 2013; Webster et al., 2003) and such incentive will be pronounced to a greater degree among individuals with high goal commitment (McFarland \& Miller, 1994). This will happen as the goal is attainable from the perspective of highly committed individuals and that different levels of goal commitment will result in different levels of performance. An attainable goal leads to high goal commitment, thus the positive effect of RPI toward performance is enhanced by the 
individual's high commitment toward the assigned goal that exists because the goal is attainable (Locke \& Latham, 2002). The interaction between these two factors will in turn affect performance, as individuals with high goal commitment will be encouraged not only to "meet" the goal, but also to "beat" the goal in the RPI present condition.

This study contributes to the behavioural management accounting literature - particularly in the field of RPI, feedback and goal setting by showing that the positive effect of RPI on performance is enhanced to a greater degree by an individual's high goal commitment. Although the relationship among these factors are considered important to be examined, there is still limited evidence regarding how the RPI - as a relative form of feedback - can be used strategically alongside goal setting elements to enhance an individual's performance in a condition when the monetary incentive is constantly held (Luft, 2016a; 2016b). In terms of the feedback-goal relationship, Renn (2003) used data from a field study to explain the moderating effect of goal commitment on the relationship between perceived feedback and work performance. This study complements the findings discussed in Renn's (2003) study by providing experimental evidence related to the relationship among feedback - manifested by RPI, goal setting - represented by goal difficulty and goal commitment, and performance.

Finally, this study also contributes to the current organisational practice by providing an empirical evidence on how RPI and goal setting elements can be used strategically by an organisation to enhance employees' performance. Given that the interaction between RPI and goal setting significantly influence performance, organisations may reap benefits if these factors can be implemented strategically in accordance with organisational needs and objectives. Since firms may often be reluctant to provide RPI because of its potential detrimental effect (Hannan et al., 2013; Luft, 2016a), this study provides evidence that RPI can be beneficial to the organisation. Also, the findings of this study indicate the importance of ensuring that RPI is provided among employees with high goal commitment - resulting from an attainable assigned goal - to ensure that the provision of RPI can bring benefit to the organisation. An example of this mechanism is the provision of periodical performance results of employees in one subunit or department. In this case, a firm needs to consider the degree of employees' goal commitment before deciding to provide the RPI, so that the positive effect of RPI would be enhanced to a greater degree and eventually is beneficial for the organisation. 


\section{Future Research and Limitations}

There are several limitations of this study. Firstly, this study only considers the provision of two RPI-related conditions, RPI present condition manifested by a public-type RPI where all participants can observe both their own performance and performance of other participants in their session, and the RPI absent condition where no information was given. Future research may consider implementing the "private-type" of RPI (Tafkov, 2013) where participants receive only their own performance without receiving any relative information regarding performance of other participants. Secondly, this study only applies goal commitment through two different levels of goal difficulty (attainable and unattainable). Future research may also look at multiple levels of goal difficulty (e.g. low, medium and high) and examine how these goal difficulty levels may affect individual's goal commitment.

Lastly, this study also has a limitation related to experiment task. To establish a task that resembles Tafkov's (2013) research, this study uses a similar type of task (30 multiplication problems) with a fixed amount of period (five rounds). This may not represent the current condition in a contemporary workplace setting where individuals typically engage in different types of tasks over time (Bonner et al., 2000). Therefore, future research may consider implementing a different type of task for each period, or same task with different dimensions over the periods, so that it can resemble the current workplace condition in a more precise way.

\section{References}

Bonner, S.E., Hastie, R., Sprinkle, G.B., \& Young, S.M. (2000). A review of the effects of financial incentives on performance in laboratory tasks: Implications for management accounting. Journal of Management Accounting Research, 12(1), 19-64. http://dx.doi.org/10.2308/jmar.2000.12.1.19

Bonner, S.E., \& Sprinkle, G.B. (2002). The effects of monetary incentives on effort and task performance: Theories, evidence, and a framework for research. Accounting, Organizations and Society, 27(4-5), 303-345. http://dx.doi. org/10.1016/S0361-3682(01)00052-6

Brown, D.J., Harris, D.L., Heller, D., \& Keeping, L.M. (2007). Antecedents and consequences of the frequency of upward and downward social comparisons at work. Organizational Behavior and Human Decision Processes, 102(1), 59-75. http://dx.doi.org/10.1016/j.obhdp.2006.10.003

Coffey, B., \& Maloney, M.T. (2010). The thrill of victory: Measuring the incentive to win. Journal of Labor Economics, 28(1), 87-112. http://dx.doi. org $/ 10.1086 / 648318$ 
Fatseas, V.A., \& Hirst, M.K. (1992). Incentive effects of assigned goals and compensation schemes on budgetary performance. Accounting and Business Research, 22(88), 347-355. http:/ / dx.doi.org/10.1080/00014788.1992.9729450

Festinger, L. (1954). A theory of social comparison processes. Human Relations, 7(2), 117-140. http://dx.doi.org/10.1177/001872675400700202

Frederickson, J.R. (1992). Relative performance information: The effects of common uncertainty and contract type on agent effort. The Accounting Review, 67(4), 647-669.

Greenberg, J., Ashton-James, C.E., \& Ashkanasy, N.M. (2007). Social comparison processes in organizations. Organizational Behavior and Human Decision Processes, 102(1), 22-41. http:/ / dx.doi.org/10.1016/j.obhdp.2006.09.006

Hannan, R.L., Krishnan, R., \& Newman, A.H. (2008). The effects of disseminating relative performance feedback in tournament and individual performance compensation plans. The Accounting Review, 83(4), 893-913. http://dx.doi.org/10.2308/accr.2008.83.4.893

Hannan, R.L., McPhee, G.P., Newman, A.H., \& Tafkov, I.D. (2013). The effect of relative performance information on performance and effort allocation in a multi-task environment. The Accounting Review, 88(2), 553-575. http:// dx.doi.org/ 10.2308/accr-50312

Hilton, R.W., \& Platt, D.E. (2011). Managerial accounting: Creating value in a global business environment (9th edition). New York, NY: McGraw-Hill/Irwin.

Hollenbeck, J.R., \& Klein, H.J. (1987). Goal commitment and the goal-setting process: Problems, prospects, and proposals for future research. Journal of Applied Psychology, 72(2), 212-220. http://dx.doi.org/10.1037/0021-9010. 72.2 .212

Hollenbeck, J.R., Williams, C.R., \& Klein, H.J. (1989). An empirical examination of the antecedents of commitment to difficult goals. Journal of Applied Psychology, 74(1), 18-23. http:/ / dx.doi.org/10.1037/0021-9010.74.1.18

Holmstrom, B. (1982). Moral hazard in teams. The Bell Journal of Economics, 13(2), 324-340. http:/ / dx.doi.org/10.2307/3003457

Kelly, K.O., Webb, R.A., \& Vance, T. (2015). The interactive effects of ex post goal adjustment and goal difficulty on performance. Journal of Management Accounting Research, 27(1), 1-25. http:/ / dx.doi.org/10.2308/jmar-50729

Klein, H.J. (1991). Further evidence on the relationship between goal setting and expectancy theories. Organizational Behavior and Human Decision Processes, 49(2), 230-257. http://dx.doi.org/10.1016/0749-5978(91)90050-4

Klein, H.J., \& Wright, P.M. (1994). Antecedents of goal commitment: An empirical examination of personal and situational factors. Journal of Applied Social Psychology, 24(2), 95-114. http://dx.doi.org/10.1111/j.1559-1816.1994. tb00560.x

Kramer, S., Maas, V.S., \& van Rinsum, M. (2016). Relative performance information, rank ordering and employee performance: A research note. Management Accounting Research, 33, 16-24. http://dx.doi.org/10.1016/j. mar.2016.03.004 
Latham, G.P., \& Locke, E.A. (1991). Self-regulation through goal setting. Organizational Behavior and Human Decision Processes, 50(2), 212-247. http:/ / dx.doi.org/10.1016/0749-5978(91)90021-K

Lee, J.S., Keil, M., \& Wong, K.F.E. (2015). The effect of goal difficulty on escalation of commitment. Journal of Behavioral Decision Making, 28(2), 114129. http://dx.doi.org/10.1002/bdm.1835

Lee, T.W., Locke, E.A., \& Phan, S.H. (1997). Explaining the assigned goalincentive interaction: The role of self-efficacy and personal goals. Journal of Management, 23(4), 541-559. http://dx.doi.org/10.1177/0149206397023 00403

Locke, E.A. (1996). Motivation through conscious goal setting. Applied and Preventive Psychology, 5(2), 117-124. http://dx.doi.org/10.1016/S0962-1849(96) 80005-9

Locke, E.A., \& Latham, G.P. (2002). Building a practically useful theory of goal setting and task motivation: A 35-year odyssey American Psychologist, 57(9), 705-717. http://dx.doi.org/10.1037//0003-066X.57.9.705

Locke, E.A., \& Latham, G.P. (2006). Enhancing the benefits and overcoming the pitfalls of goal setting. Organizational Dynamics, 35(4), 332-340. http:// dx.doi.org/10.1016/j.orgdyn.2006.08.008

Luft, J. (2016a). Cooperation and competition among employees: Experimental evidence on the role of management control systems. Management Accounting Research, 31(June), 75-85. http://dx.doi.org/10.1016/j.mar.2016.02.006

Luft, J. (2016b). Management accounting in the laboratory and in social context: Four contrasts, 1975-2014. Accounting, Organizations and Society, 49(February), 9-20. http://dx.doi.org/10.1016/j.aos.2015.08.001

Mahlendorf, M.D., Kleinschmit, F., \& Perego, P. (2014). Relational effects of relative performance information: The role of professional identity. Accounting, Organizations and Society, 39(5), 331-347. http://dx.doi.org/ 10.1016/j.aos.2014.05.001

McFarland, C., \& Miller, D.T. (1994). The framing of relative performance feedback: Seeing the glass as half empty or half full. Journal of Personality and Social Psychology, 66(6), 1061-1073. http://dx.doi.org/10.1037/00223514.66.6.1061

Mohamed, R., Wee, S.H., Abdul Rahman, I.K., \& Abdul Aziz, R. (2014). The relationship between strategic performance measurement system and organisational capabilities: The role of beliefs and boundary control systems. Asian Journal of Business and Accounting, 7(1), 107-142.

Murthy, U.S., \& Schafer, B.A. (2011). The effects of relative performance information and framed information systems feedback on performance in a production task. Journal of Information Systems, 25(1), 159-184. http:// dx.doi.org/ 10.2308/jis.2011.25.1.159

Newman, A.H., \& Tafkov, I.D. (2014). Relative performance information in tournaments with different prize structures. Accounting, Organizations and Society, 39(5), 348-361. http://dx.doi.org/10.1016/j.aos.2014.05.004 
Nordstrom, R., Lorenzi, P., \& Hall, R.V. (1991). A review of public posting of performance feedback in work settings. Journal of Organizational Behavior Management, 11(2), 101-124. http://dx.doi.org/10.1300/J075v11n02_07

Presslee, A., Vance, T.W., \& Webb, R.A. (2013). The effects of reward type on employee goal setting, goal commitment, and performance. The Accounting Review, 88(5), 1805-1831. http://dx.doi.org/10.2308/accr-50480

Renn, R.W. (2003). Moderation by goal commitment of the feedback-performance relationship: Theoretical explanation and preliminary study. Human Resource Management Review, 13(4), 561-580. http://dx.doi.org/10.1016/ j.hrmr.2003.11.003

Tafkov, I.D. (2013). Private and public relative performance information under different compensation contracts. The Accounting Review, 88(1), 327-350. http://dx.doi.org/10.2308/accr-50292

Webster, J.M., Duvall, J., Gaines, L.M., \& Smith, R.H. (2003). The roles of praise and social comparison information in the experience of pride. Journal of Social Psychology, 143(2), 209-232. http://dx.doi.org/10.1080/ 00224540309598441

Wood, J.V. (1996). What is social comparison and how should we study it? Personality and Social Psychology Bulletin, 22(5), 520-537. http://dx.doi.org/ $10.1177 / 0146167296225009$

Wright, P.M. (1992). An examination of the relationships among monetary incentives, goal level, goal commitment, and performance. Journal of Management, 18(4), 677-693. http://dx.doi.org/10.1177/014920639201800405 
